\title{
O BRINQUEDO E A BRINCADEIRA NA EDUCAÇÃO INFANTIL
}

\author{
Dasny Pestana de Pinto \\ Renata Regina de Araújo do Monte ${ }^{2}$ \\ Rosângela Silva Santos 3 \\ Suely Francisca Soares Jacobes ${ }^{4}$ \\ Vanildes Célia de Paulas
}

RESUMO: Este artigo tem como tema o brinquedo e brincadeira na educação infantil, como linha de pesquisa: a docência na educação infantil. Como objetivo proporcionar situações de ensino-aprendizagem através de atividades lúdicas; utilizar as atividades lúdicas como recurso pedagógico junto às crianças, apresentar as diversidades de brinquedos e brincadeiras às crianças. Os conteúdos trabalhados neste artigo sobrevêm na linguagem, oralidade, organização e orientação espacial, entre outros. Os educadores têm conhecimentos específicos destinados à educação infantil, desse modo as atividades lúdicas desenvolvidas junto às crianças acontecem através de brincadeiras livres e dirigidas de acordo com o planejamento e a avaliação por meio da observação, registro das práticas desenvolvidas e interesse e participação nas atividades propostas. Para Cousineau (2004, p. 63), "O tempo é uma criança brincando", escreveu Heráclito, um sábio da era clássica, movendo peças num tabuleiro: o reino pertence a uma criança, essa metáfora reflete o modo como lúdico permite as crianças praticarem os papéis que irão desempenhar no futuro através da imaginação, ou pela alegria pura e simples da liberdade de movimento.

Palavras-chaves: Brinquedo. Brincadeira. Educação Infantil. Planejamento.

\section{INTRODUÇÃO}

A temática escolhida, para a realização deste artigo tem como tema: o Brinquedo e as brincadeiras na educação infantil e como linha de pesquisa: Docência na Educação Infantil.

\footnotetext{
I Graduada em Pedagogia, Docência para Educação Infantil e Anos Iniciais do Ensino Fundamental e na Empresa pelo UNIVAG - Centro Universitário Várzea Grande, Especialista em Educação Infantil pela Faculdade Mantenense dos Vales Gerais - INTERVALE.

${ }^{2}$ Graduada em Pedagogia pela Universidade Federal de Mato Grosso - UFMT, Especialista em Alfabetização Matemática pela Faculdade São Bráz.

${ }^{3}$ Graduada em Pedagogia pela UNOPAR - Universidade Norte do Paraná, Especialista em Educação Infantil e Alfabetização pela Faculdade Afirmativo.

4 Graduada em pedagogia pela UNIP - Universidade Paulista, Graduada em História pela UFMT Universidade Federal de Mato Grosso, Especialista em Gestão Municipal pela UNEMAT - Universidade do Estado de Mato Grosso, Especialista em Educação Especial pelo UNINTER - Centro Universitário Internacional, Especialista em Educação Infantil pela Faculdade UniBF.

5 Graduada em Pedagogia pela Faculdade Mantenense dos Vales Gerais, Especialista em Educação Infantil e Séries Iniciais no Ensino Fundamental pela Faculdade Integrada de Ariquemes.
} 
A elaboração dessa temática justifica-se pelo fato da mesma ser bastante atual e de grande relevância para educação, em especial para a educação infantil, etapa tão importante do aprendizado. Portanto a sua elaboração justifica-se na importância que o brinquedo e as brincadeiras têm nesse período do desenvolvimento humano que é a infância, pois os jogos e brinquedos têm, em cada momento da vida da criança, uma função, um significado diferente e especial para quem dela participa.

Os educadores têm dado o devido valor ao brinquedo e as brincadeiras como elemento importante no desenvolvimento infantil, bem como recurso de ensino e a aprendizagem?

Os objetivos elencados são: proporcionar situações de ensino-aprendizagem através de atividades lúdicas; utilizar as atividades lúdicas como recurso pedagógico junto às crianças, apresentar as diversidades de brinquedos e brincadeiras às crianças.

Os conteúdos desenvolvidos neste artigo, em conformidade a linha de pesquisa escolhida: Docência na Educação Infantil serão: a linguagem, a socialização, os movimentos, a coordenação motora fina e ampla, lateralidade, organização e orientação espacial.

Enfim, para a realização deste trabalho buscou-se uma pesquisa bibliográfica, com autores e seus conceitos que tratam do tema, tais como: Cória-Sabini (2009); Lucena (2009), Kishimoto (200I), Luckesi, (2000), Moyles (2002), entre outros.

\section{DESENVOLVIMENTO}

De acordo com Vercelli \& Stangherlim (2015, p. 13), a Educação Infantil é a primeira etapa da Educação Básica, objetivando o desenvolvimento da criança até seis anos de idade. A Lei de Diretrizes e Bases da Educação (LDB 9.394/96) em seu artigo 29 e 30, diz que a educação infantil é ofertada nas creches, ou entidades equivalentes, para crianças de até três anos de idade; pré-escolas, para crianças de quatro a seis anos de idade.

Para Constantino et al. (2003, p. 13), a mesma deve fazer parte do sistema educacional regular, através da política de educação infantil aonde a criança é o sujeito histórico, permitindo-lhe o desenvolvimento pleno e equilibrado, promovendo sua formação enquanto cidadã.

O ser humano é um ser lúdico, onde na infância a sua ludicidade é expressada de modo mais intenso, como nos garante Montenegro et al. (2007, p. 259) a criança precisa ver 
olhada como um ser lúdico, portanto, necessita exercer e viver de modo contínuo esse seu aspecto.

O que acontece é que algumas instituições, voltadas às crianças menores, não reservam esse tempo destinado ao "brincar". De acordo com Zatz \& Zatz (2006, p. 15), as crianças freqüentam mais cedo à escola, que estão mais preocupadas com seus programas e currículos, não reconhecendo a brincadeira e sua importância. É preciso compreender que a criança a todo o instante se socializa por meio do brincar, esta atitude lhe é peculiar, pois desde que nasce a mesma interage com o mundo e cria suas percepções, sendo que deste brincar incluem os jogos, brinquedos e as diversões.

Segundo Marinho (2007, p. 83) o jogo educativo permite a criança aprendizagem, vivências corporais, experimentar sensações e explorar as possibilidades de movimento do seu corpo e do espaço, adquirindo um saber mais global com base em situações concretas.

O emprego pedagógico do lúdico em sala de aula permite a mudança cotidiana em experiência criadora em presença dos quais os alunos são motivados irem à escola, a pedagogia origina o desenvolvimento cognitivo por meio da aprendizagem de modo mais instituída nos aspectos culturais e simbólicos.

A ludicidade surge no processo ensino-aprendizagem, sendo que nessa perspectiva, a brincadeira, o jogo e o brinquedo, enfim, as atividades lúdicas, devem se fazer presentes como recurso didático no processo educacional, principalmente na educação infantil e nas séries iniciais do ensino fundamental. Marinho (2007, p. 8I) afirma que compreender esse universo lúdico torna-se imprescindível ao bom desenvolvimento do trabalho pedagógico efetivado pelo professor.

O educador necessita usar essas ferramentas para que motive o educando com a intenção específica para que aprenda de modo integral e dinâmico, deve também levar em consideração a realidade do aluno permitindo que seja sempre capaz de produzir e criar.

Dessa forma, como diz Soto et al. (2009, p. 204), o professor deixa de ser visto apenas como um transmissor de conhecimentos tornando-se gerenciador de entendimento, mediador do processo de aprendizagem e preparando os espaços para o diálogo e interação. E mais ainda, compete ao professor despertar nos alunos o desejo pelo conhecimento, por meio de mecanismos que os motivem, de modo natural realizem seus objetivos propostos. 
O lúdico, portanto, é uma maneira extraordinária de aprendizagem, permitindo a criança experimentar aquilo que é vivenciado, sendo que os jogos ficam mais atraentes, quando articula com os mais variados conhecimentos adquiridos.

Marinho et al. (2007, p. 83), evidencia a importância das atividades lúdicas, especialmente do jogo, na aprendizagem das crianças, destaca que são fontel de prazer e descoberta para a criança.

O lúdico para este autor é importante, podendo ser empregado na escola como um dos recursos didáticos no processo de ensino-aprendizagem, contribuindo com as atividades didático-pedagógicas, bem como considera o jogo educativo imprescindível, pois permite à criança uma aprendizagem através de vivências corporais, aonde o movimento corporal nesse "jogar" é importante para o processo de desenvolvimento infantil, pois garante a aprendizagem das crianças, presente em todas as atividades lúdicas.

O período da infância é a fase da vida aonde as brincadeiras satisfazem suas necessidades, desejos, sendo que uma forma de privilégio da criança está na capacidade de inserir em sua própria realidade sua imaginação, por meio do brincar que a ela aprende, organiza, constrói, desconstrói sua realidade de mundo.

Löwen (1990, p. 58), nos garante que a ludicidade se inicia na primeira infância e que mantemos nossa capacidade de brincar na vida adulta, mesmo que a ludicidade não seja algo mais o dominante nesse comportamento na maturidade.

O brinquedo educativo obtém expressão na educação infantil, como recurso ao ensino, desenvolve e educa de modo prazeroso, pode se tornar material de diversas formas para ensinar. Este tipo de brinquedo requer que se olhe para a infância e sua função pedagógica. Portanto brinquedo educativo assume uma finalidade pedagógica, sendo instrumento importante para situações de ensinar, aprender e desenvolver.

Kishimoto (200I, p. 36) afirma as situações lúdicas quando são intencionalmente criadas pelo adulto para estimular certos tipos de aprendizagem surge à dimensão educativa, sendo necessário manter as condições para a expressão do jogo, a ação intencional da criança para brincar, assim o educador potencializa as situações de aprendizagem.

As situações lúdicas desenvolvidas pelo adulto objetivando motivar os tipos de aprendizagem relacionam-se a sua função educativa, sendo condições expressas no jogo, onde o educador tem um grande potencial para ensinar e o aluno para aprender. 
Kishimoto (200I, p. 37), diz que usar o jogo na educação infantil implica em levar para ensino-aprendizagem os meios necessários para a construção do conhecimento, mediante as propriedades do lúdico, do prazer, da capacidade de iniciação e ação ativa e motivadora.

Segundo Almeida (1995, p. II), o aspecto lúdico proporciona diversão, prazer, desprazer, quando sua escolha é voluntária, tem como fim a função educativa, fazendo do brincar um ato de ensinar qualquer coisa. A educação lúdica com a criança obtém forma transacional direcionada ao conhecimento, preparando o pensamento individual em substituições ao pensamento coletivo.

Para Muniz (2002, p. 49), é através do brinquedo e da brincadeira que as crianças aumentam seu vocabulário, se estabelecem no tempo e espaço, adquirem conhecimento acerca do seu meio ambiente e melhor se localizam nele.

Cruz (2000, p. 123) afirma a importância da função do brincar no pensamento da criança, para ele através do brincar torna-se fácil entrar no clima de faz-de-conta, compartilhar metáforas e símbolos, brincar e jogar, usar os recursos lúdicos infantis.

Portanto, para este autor a criança se prepara para a vida através do lúdico, conhecendo sua cultura, seu meio onde vive, interage e adaptam-se as condições de vida que lhe é oferecido, aprendendo a cooperar e a conviver, competir como um ser social.

Para Stori (2003, p. 64), ao brincar, através das situações de imaginação, a criança entra no mundo do adulto, representado papéis desenvolve a sua capacidade comunicativa, aptidão física, intelectual e verbal, possibilitando uma aprendizagem efetiva e prática, significativa. Entende-se que esse direito ao respeito não significa a aceitação de que a criança habite em um mundo autônomo do adulto, tampouco que deva ser deixada entregue apenas à sua educação alfabetizada, recusando-se assim, a interferência do adulto e brincadeiras, no processo.

Marcelino (1996, p. 38), diz que é de suma importância assegurar à criança o tempo e os espaços necessários ao lúdico, ao lazer, a criatividade, a participação cultural, ao exercício do prazer de viver. (MARCELINO, I996, p. 38)

O autor Luckesi (200o, p. 20) afirma que uma educação lúdica tem na sua base a compreensão de que o ser humano é um ser em movimento, permanentemente construtivo de si mesmo, contrariando a pedagogia tradicional que concebe o ser humano como um ser pronto. 
A atividade lúdica propicia um estado de consciência livre dos controles do ego, por isso mesmo criativo. O nosso ego, como foi construído, em nossa história pessoal de vida, na base de ameaças e restrições, é muito constritivo, centrado em múltiplas defesas. Ele reage à liberdade que traz a atividade lúdica em si mesma. Por isso, uma educação centrada em atividades lúdicas tem a possibilidade, de um lado, de construir um eu (não um ego) saudável em cada um de nós, ou, por outro lado, vagarosamente, auxiliar a transformação do nosso ego construtivo num Eu saudável. Educar crianças ludicamente é estar auxiliando-as a viver bem o presente e preparar-se para o futuro. Educar ludicamente adolescentes e adultos significa estar criando condições de restauração do passado, vivendo bem o presente e construindo o futuro (LUCKESI, 2000, p. 21-22).

Ao brincar com uma criança, estamos ajudando-a a aprender a lidar com seus impulsos, buscando a satisfação de seus desejos, vencendo as frustrações, estamos agindo de modo estratégico. De acordo com Emerique (2003, p. 17-18), o brincar, jogar com a imaginação, fantasiar favorecem a saúde mental.

O uso do brinquedo pela criança é um instrumento de transformação e também de invenção e imaginação. Com isso ela desenvolve novos conceitos para compreender o mundo em que vive.

Para Allesandrin (1999, p. I13), tudo se transforma num brinquedo, sendo assim o brincar, imaginar, criar, fazer, construir, contar, sonhar, são palavras que fazem parte da vida de cada criança.

$\mathrm{Na}$ história no Brasil, as referências a brinquedos praticamente inexistem, estudiosos adotam a história francesa para tal. Mas se sabe que seu surgimento aconteceu na antiga Roma e Grécia, as primeiras ideias e reflexões acerca do brincar e os brinquedos.

Kishimoto (1988, p. 44), relata que a valorização do jogo, chega ao Brasil na década de 80 , através das brinquedotecas, a criação de associações de brinquedotecas, dos congressos, da produção científica acerca deste tema, bem como o interesse dos empresários no aumento do seu faturamento no investimento de novos produtos.

Todos aqueles instrumentos, feitos de diversos materiais, são significativos e devem ser adequados a cada faixa etária, por isso deve haver uma escolha consciente pelos pais e pela escola. Assim Maia (2000, p. 8I apud Lehenbauer et. al. 2005, p. 44I), destaca que o brinquedo é fundamental elemento voltado ao desenvolvimento cultural da criança: "o 
brinquedo dirige o desenvolvimento" (VYGOTSKY, I991, p. I46 apud LEHENBAUER et al. 2005, p. 44I).

A imaginação para Vygotsky (199I) apud Lehenbauer et al. (2005, p. 44I) seria o brinquedo sem ação, ressalta a necessidade de intervenção, problematização do brincar da criança, visto que este se origina da imitação de situações que a criança confronta diariamente, ao imitar situações do seu dia-a-dia através do brincar, a criança entra no mundo adulto.

Este autor realiza uma análise sócio-histórica do brincar infantil em sua obra, onde o brincar é entendido como uma atividade social da criança, com natureza e origem específica e fundamental para o seu desenvolvimento cultural. $O$ brincar como compreensão da realidade e facilitador na construção da Zona de Desenvolvimento Proximal.

A recreação contribui na formação motora, possibilitando que a criança consiga, por meio dela, sentir de modo livre, espontânea e natural, desenvolvendo os aspectos motores e cognitivos. Para a criança a importância da recreação está relacionada ao entretenimento, ao lúdico, aumentando suas experiências, desenvolvendo e atendendo as suas necessidades biológicas.

Com alegria despertamos nela o gosto pela vida e o enfrentamento dos desafios com segurança e confiança. Quando estão brincando, as crianças adotam papéis sociais variados, relações, generalizando para outras situações e internalizando modelos e valores dos adultos. O brincar permite que a mesma desenvolva sua identidade e autonomia, perceba diferentes modos de pensar e de agir e construa sua personalidade.

Entender que as atividades lúdicas, desde que bem direcionadas e com objetivos, torna-se uma ferramenta à educação e o ensinamento na educação infantil, pois carregam o simbólico, cabendo seu uso pela escola e pela educação por estarem na formação do homem para outro tipo de ideologia, sendo esta, mais cooperativa, mais humana e não violenta.

Os professores devem garantir um tempo à exploração da linguagem das crianças, através do brincar dirigido, os professores terão a oportunidade de aumentar o vocabulário, discutir processos lúdicos anteriores e, de modo geral, ampliar o pensamento da criança por meio de discussões e conversas.

As oportunidades de explorar as respostas, os entendimentos e mal-entendidos das crianças vão ocorrer na atmosfera mais relaxada do segundo momento de brincadeiras e nos 
posteriores, quando o diálogo provavelmente será mais significativo e temporalmente relacionado (MOYLES, 2002, p. 54).

A escola ainda fica presa neste modelo, não assumindo de modo profissional ou material as atividades que poderão ser proporcionadas aos alunos por meio do lúdico.

Marinho et al. (2007, p. 9I), afirma que a aprendizagem ocorre através de modo mais significativo quando a criança puder vivenciar as situações pedagógicas por meio do movimento, assim experimentando, realizando, sentindo, percebendo através do corpo. Para este mesmo autor as brincadeiras, os jogos exercem um papel principal nessa vivência, fazendo parte do universo infantil. A escola, portanto precisa dar prioridade em projeto político-pedagógico o desenvolvimento de aiividades voltadas ao o lúdico.

A brincadeira objetiva melhora na auto-estima, desenvolvimento da linguagem oral e gestual, auxiliar na elaboração das emoções e sentimentos e na construção de regras sociais.

O brincar é uma das atividades essenciais para o desenvolvimento da identidade e da autonomia. Através das brincadeiras as crianças desenvolvem capacidades importantes, tais como: atenção, a imitação, a memória, a imaginação, bem como amadurecem também algumas capacidades de socialização, por meio da interação e da utilização e experimentação de regras e papéis sociais (BRASIL, 1998, p. 22).

Dessa forma os pequenos quando brincam, desempenham papéis sociais constituindo relações e generalizações para outras situações e internalização de modelos e valores dos adultos.

Newman \& Holzman (2002, p. 120), exemplificam bem isso, dizendo que quando brincam de mamãe e papai, seguem regras e imitam papéis sociais, rompendo com a organização da vida cotidiana, pois a criança não é a mãe. Além do mais, a brincadeira permite o desenvolvimento da identidade e da autonomia, da constituição da personalidade.

Elkonin (1998, p. 325) apud Costa \& Gontijo (20II, p. 272) diz que a utilização do lúdico dos objetos é característica do brincar das crianças. Desse modo, quando as crianças incorporam aos objetos o jogo estes deixam de ter significado habitual adquirindo significado lúdico, conforme o qual a criança os denomina e com eles interage.

Embora atualmente a escola de educação infantil tenha favorecido a utilização dos brinquedos e das brincadeiras para beneficiar sua aprendizagem, entretanto há ainda muito a ser feito para ser empregada de fato pelas educadoras. 


\section{CONCLUSÃO}

O presente artigo se propôs orientar a prática pedagógica do docente na educação infantil através da utilização dos brinquedos e das brincadeiras nessa modalidade de ensino. A sua elaboração permitiu analisar aspectos do desenvolvimento infantil através do emprego do lúdico, bem como compreender a importância do brincar para as crianças.

O estudo acerca dos brinquedos e brincadeiras propicia conhecimento que colaboram na formação profissional dos futuros educadores modernos, uma vez que os mesmos escolhem desenvolver as suas competências individuais e profissionais, uma vez que elas são fundamentais para atingir os objetivos educacionais das crianças, entretanto é de suma importância que este profissional tenha uma visão ampla acerca dos aspectos pedagógicos do lúdico, dessa forma as atividades lúdicas, precisa estar presentes como recurso didático no seu processo educacional, principalmente na educação infantil.

O professor ao elaborar seu planejamento o lúdico deve estar alinhando a sua prática pedagógica, estando atento às exigências da mesma.

Através da realização deste artigo, é possível constatar a relevância deste tema para a pedagogia. Assim educadores deverão está inseridos de forma competente em suas atribuições iniciais, além de todas as habilidades e conhecimentos necessários ao desempenho de suas funções.

É indispensável que esses mesmos educadores busquem o aperfeiçoamento contínuo e estejam sempre preparados para desenvolver boas práticas educativas voltadas ao crescimento e desenvolvimento dos seus alunos; além de permanecerem atentos no comportamento desses pequenos e na dinâmica do seu desenvolvimento infantil para auxiliarem em seu processo de aprendizagem.

\section{REFERÊNCIAS}

ALLESSANDRINI, Cristina Dias. (org.) Tramas Criadoras na construção do 'ser si mesmo'. São Paulo: Casa do Psicólogo. 1999.

ALMEIDA, Paulo Nunes de. Educação lúdica: técnicas e jogos pedagógicos. São Paulo: Loyola, 1995. 
BRASIL. Ministério da Educação e do Desporto. Secretaria de Educação Fundamental. Referencial curricular nacional para a educação infantil - Ministério da Educação e do Desporto, Secretaria de Educação Fundamental. Brasília: MEC/SEF, 1998. 3v.: il.

COSTA, Dânia Monteiro Vieira Costa; GONTIJO, Cláudia Maria Mendes. A linguagem oral como elemento integrante da brincadeira. Cadernos de Pesquisa v.4I n.I42 jan./abr. 201 . Disponível em http://www.scielo.br. Acesso em 02/o9/202I.

CONSTANTINO, Elizabeth Piemonte. et. al. Um olhar da psicologia sobre a educação: diagnóstico e intervenção na infância e na adolescência. São Paulo: Arte \& Ciência, 2003.

EMERIQUE, P.S. Brincaprende: dicas lúdicas para pais e professores. Campinas, SP: Papirus, 2003.

KISHIMOTO, Tizuko Morchida. O jogo e a Educação Infantil. In: Jogo, Brinquedo, Brincadeira e a Educação. São Paulo. Cortez, 5 ed., 20oI.

LEHENBAUER, Silvana; PICAWY, Maria Maira; STEYER, Vivian Edite; WANDSCHEER, Maria Sirlei. O ensino fundamental no século XXI: questões e desafios. Canoas: Ed. ULBRA, 2005.

LÖWEN, Alexander. Amor, sexo e seu coração. São Paulo: Summus, I99o.

LUCKESI, Cipriano Carlos (org.). Ludopedagogia - Ensaios r: Educação e Ludicidade. Salvador: Gepel, 200o. v.I.

Educação, ludicidade e prevenção das neuroses futuras: uma proposta pedagógica a partir da Biossíntese. In: LUCKESI, C. C. (org.) Ludopedagogia: ensaios I: Educação e Ludicidade. Salvador: Universidade Federal da Bahia, Faculdade de Educação, Programa de Pós-Graduação em Educação, Gepel, 2000. 
MARCELINO, Nelson Carvalho. Estudos do lazer: uma introdução. Campinas. São Paulo: autores associados 1996.

MARINHO, Hermínia Regina Bugeste. Pedagogia do movimento: universo lúdico e psicomotricidade. 2 ed. Curitiba: Ibpex, 2007.

MONTENEGRO, Eduardo. et. al. Imaginário e representações sociais: corpo, educação física, cultura e sociedade. Maceió: EDUFAL, 2007.

MOYLES, Janet R. Só brincar? O papel do brincar na educação infantil. Tradução Maria Adriana Veronese. Porto Alegre: Artmed Editora, 2002.

MUNIZ, Cristina (org.) Esconderijos.... Rio de Janeiro: 7Letras, 2002.

NEWMAN, Fred; HOLZMAN, Lois. Lev Vygotsky: cientista revolucionário. Edições Loyola, São Paulo: 2002.

SOTO, Ucy; MAYRINK, Mônica Ferreira; GREGOLIN, Isadora Valencise (org.). Linguagem, Educação e Virtualidade: Experiências e reflexões. São Paulo: Cultura Acadêmica, 2009.

STORI, Norberto. (org.) O despertar da sensibilidade na educação. São Paulo: Instituto Presbiteriano Mackenzie: Cultura Acadêmica Editora, 2003.

VERCELli, Ligia de Carvalho Abões; STANGHERLIM, Roberta. (orgs.) Formação de professores e práticas pedagógicas na Educação Infantil. Jundiaí, Paco Editorial, 2015.

ZATZ, Sílvia; ZATZ, Sérgio Halaban. Brinca comigo!: tudo sobre brincar e os brinquedos. São Paulo: Marco Zero, 2006. 